BANGLADESH J CHILD HEALTH 2010; VOL 34 (3): 92-98

\title{
Congenital Muscular Torticollis: A Descriptive Study of 16 Cases
}

\author{
BIJOY KRISHNA DAS ${ }^{1}$, ABDUL MATIN² ${ }^{2}$ RANJIT RANJAN ROY ${ }^{3}$, MD. RAFIQUL ISLAM ${ }^{4}$, \\ REZAUL ISLAM ${ }^{5}$, RITA KHAN ${ }^{6}$
}

\begin{abstract}
Background and study aim: Torticollis is the postural deformity of head and neck. Congenital Muscular Torticollis (CMT) is a postural deformity of head and neck detected at birth or shortly after birth, primarily resulting from unilateral shortening of Sternocleidomastoid muscle (SCM). In neonates and infants, patient may be cured conservatively by physiotherapy but surgery is the treatment of choice for children and adolescents. There are various techniques of surgery. Division of both sternal and clavicular head of SCM is very easy method which was practiced in this study. Here we show our experience regarding conservative and surgical management of congenital muscular torticollis in neonates, infants and older children.

Patients and Methods: This is a retrospective case study among sixteen patients of congenital muscular torticollis. The cases were enrolled consecutively between Nov' 2005 to Oct' 2008 in Bangabandhu Sheikh Mujib Medical University, Gonosasthaya Somaj Vittik Medical College Hospital, ZH Sikder Women's Medical College Hospital and different private clinics of Dhaka city of Bangladesh. Neonates and infants of were treated conservatively with physiotherapy by manual stretching and others (more than one year) were treated surgically by transection of both sternal and clavicular head of SCM under ganeral anesthesia. Operated patients were released on following post operative day with advice to start physiotherapy on same day. Acquired torticollis, ocular torticollis, neurogenic torticllis, osteogenic torticollis, congenital muscular torticollis with other diseases were excluded from the study. Parents were the informants. Purpose of the study was explained and verbal consent was taken. Written consent was taken before surgical intervention.
\end{abstract}

Results: Patients age ranged from 5 days to 15 years of which eleven were female and five male. SCM was shortened in all cases ( 9 on right side and 7 on left side). Of 16 patients, 3 neonates, 8 infants and 5 were more than 1 year of age. There was no associated anomaly. Out of 11 neonates and infants 10 cured conservatively with physiotherapy and another one significantly improved. Six were treated surgically including one failed physiotherapy till the age of one year. Post operative period was uneventful and there was no complication. Results were evaluated clinically and on the comments of parents.

Conclusion: Most of the patients of congenital muscular torticollis can be treated conservatively during infancy. Division of both sternal and clavicular head of SCM is easy and safe surgical technique for the treatment of CMT of older children and adolescents.

Key words: Congenital muscular torticollis, wryneck, conservative management, manual stretching, surgery.

1. Associate Professor and Head, Department of Paediatric Surgery, H Sikder Women's Medical College, Dhaka, Bangladesh

2. Assistant Professor, Department of Paediatrics, Shahid Shurawardy Medical College and Hospital, Dhaka, Bangladesh

3. Associate Professor, Department of Paediatrics, Shahid Shurawardy Medical College and Hospital, Dhaka, Bangladesh

4. Assistant Professor, Department of Paediatrics, Shahid Shurawardy Medical College and Hospital, Dhaka, Bangladesh

5. Associate Professor and Head, Department of Anesthesiology, Z H Sikder Women's Medical College, Dhaka, Bangladesh

6. Medical officer, NICR\&H, Mohakhali, Dhaka, Bangladesh

Correspondence: Dr. Bijoy Krishna Das 


\section{Introduction}

Torticollis is the postural deformity of head and neck which may be acquired or congenital. Acquired torticollis may be due to trauma, inflammatory, psychogenic or neoplastic. The most common form of congenital torticollis is congenital muscular torticollis. Other causes of congenital torticollis include postural torticollis, pterygium colli (webbed neck), SCM cysts, vertebral anomalies, odontoid hyperplasia, spina bifida, hypertrophy or absence of cervical musculature, and Arnold-Chiari syndrome. It can also be seen with clavicular fractures, especially in neonates secondary to birth trauma. Congenital muscular torticollis (CMT) is a postural deformity of head and neck detected at birth or shortly after birth, primarily resulting from unilateral fibrosis \& shortening of the Sternocleidomastoid muscle ${ }^{1-2}$. The shortening of Sternocleidomastoid muscle (SCM) results in traction of mastoid process toward the sternoclavicular joint ${ }^{3}$. The head is therefore tilted toward the involved sternocleidomastoid muscle and the chin is rotated in opposite direction. The condition is some times called "Wryneck". Torticollis is also known as twisted neck.

The incidence of CMT is one in every 300 live births ${ }^{4}$. Plagiocephaly may co-exist in $80-90 \%$ of children with $\mathrm{CMT}^{1,5}$.

Though impairment of Sternocleidomastoid muscle(SCM) function is the most frequent cause of CMT but torticollis could also result from other underlying disorders. The exact pathophysiology and etiology of sternocleidomastoid impairment in CMT is still unknown $n^{1,3-5}$.

In CMT, patient's head remain tilted toward the involved side. Child and adolescent patients can't look forward. If the patient wants to look other sides he/ she have to rotate whole body as he / she can't move the neck. Gradually patient develops facial hemihypoplasia which results in flattening and under development of the malar eminence, downward displacement of the eye, ear and angle of mouth on the affected side. It also hampers the development of facial skeletons ${ }^{1,8}$.

Children with CMT can be assigned to one of three groups $^{1}$ -

1. Children with a palpable swelling or pseudotumor of the sternocleidomastoid; 2 . Children with SCM tightness but no tumor; 3 . Children with all features of muscular torticollis without muscle tightness or tumor.

History, physical examination \& clinical progression can do the diagnosis but in some cases ocular and neurological evaluation and radiological investigation of cervical spine is necessary ${ }^{6}$.

Management depends upon the age of patient at which he/she is presented to physician. Patient of below 1 year of age, treatment is conservative - physiotherapy and above one year of age - treatment is surgery ${ }^{1,8,9,11}$.

$69 \%$ to $91 \%$ patients may cure conservatively with physiotherapy within one year of age ${ }^{1,7,8}$. Conservative management of infants with torticollis consists of positioning, gentle range of motion, and strengthening through activation of head and trunk muscles as the infant gains control of upright postures ${ }^{9,10}$.

Manual stretching is the most common form of treatment for $\mathrm{CMT}^{10}$. Proper stabilization of body of patient and hand placement of physicians/parents is vital for the success of each stretch; however, all child/ parent pairs will not be comfortable with the same method of stretching or the same stretch positions. Method of stretching can be individualized for each patient with a target to lengthening of effected Sternocleidomastoid Muscle by stretching. The severity of the torticollis, the age of the child, the tolerance of the child for handling, and the parent's ability to carry out the exercise program will determine the method of stretching. When performing stretching exercises, the position of the head and neck in flexion versus extension will impact the effectiveness of the stretch $^{9}$.

Surgery is the treatment of choice for the patient with CMT persisting after one year of age ${ }^{11}$. There are various techniques of surgery -

1. Division of both sternal and clavicular heads of $\mathrm{SCM}^{11} ; 2$. Lengthening of tight SCM by unipolar release $^{1,5}$; 3. Lengthening of tight SCM by bipolar release $^{12} ; 4$. Subperiosteal lengthening ${ }^{13} ; 5$. Endoscopic release ${ }^{14}$.

Subperiosteal lengthening, lengthening of tight SCM by unipolar or bipolar release, etc techniques are difficult and there is chance of injury to accessory nerve. Endoscopic surgery is a high-tech surgery and needs sophisticated instruments. Division of both sternal and clavicular heads of SCM is easy and there is less chance of injury to any nerves or large vessels and thus we practice this method for the treatment of children with CMT of more than one year age ${ }^{11}$. 


\section{Materials and Methods}

Sixteen cases of Congenital Muscular Torticollis (CMT) were treated from November 2005 to October 2008 in Bangabandhu Sheikh Mujib Medical University, Gonosasthaya Somaj Vittik Medical College Hospital, ZH Sikder Women's Medical College Hospital and different private clinics of Dhaka city of Bangladesh. Patients were diagnosed clinically. All the patients of torticollis with short sternocleidomastoid muscle without any other problem were included in this study. Acquired torticollis, congenital torticollis due to neurological deficit, ocular problem, and osteogenic problem were excluded from the study. There were no facial hemihypoplasia or any other associated abnormalities of our studied patients.

All of the patients were diagnosed clinically. All of the history was taken from mother.

Neonates and infants were treated conservatively with physiotherapy as out patient - none was admitted. Physiotherapy is simple - manual stretching of effected $\mathrm{SCM}$, frequent movement of head on opposite direction of chin position, lied lateral position on effected side. Patient's mother was trained accordingly. Physiotherapy was given at home by mother. Proper counseling of parents and guardians were done regarding fate and management of CMT.

Children of more than one year age were treated surgically by transection of both sternal and clavicular head of SCM under general anesthesia. Operated patients were released on following post operative day with advice to do limited physiotherapy on the same and regular physiotherapy from fifth post operative day. Out of 6 surgical patients, 5 were untreated in the neonatal and infantile period and failed physiotherapy was one.

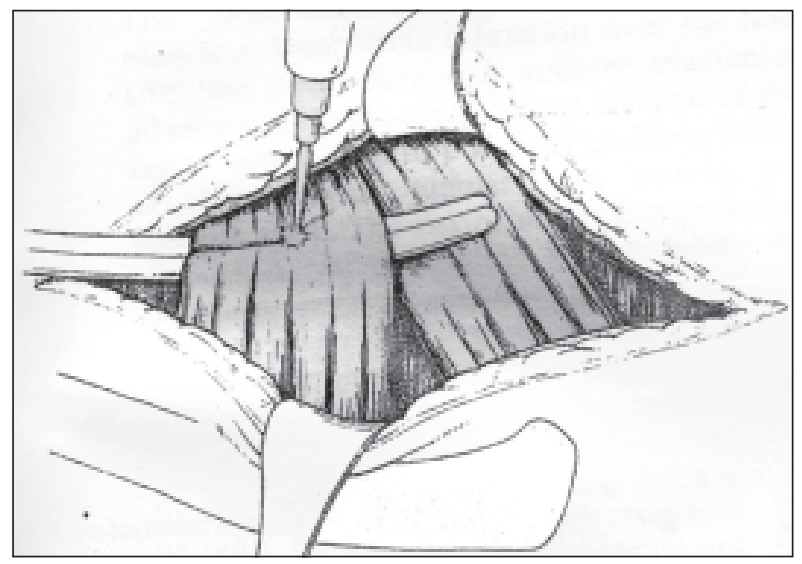

Fig.-2a : Division of SCM (Sketch)
All of the operated patients were admitted to hospital. Written informed consent was taken from parents. Under general anesthesia, an approximately $3 \mathrm{~cm}$ transverse curvilinear incision was made on skin crease line about $2-5 \mathrm{~cm}$ above and medial part of clavicle (Fig.-1) just over SCM.

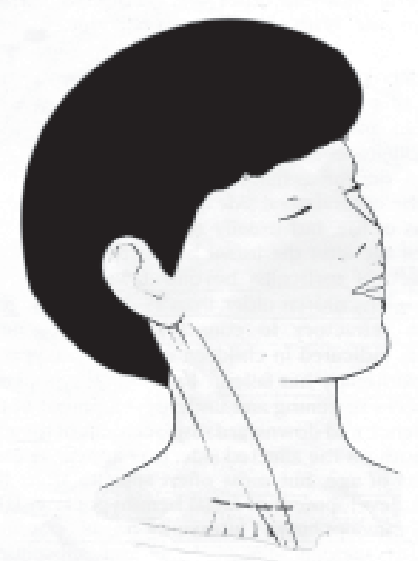

Fig.-1 : Incision line for release SCM

The platysma was divided. Subplatysmal flaps were developed along the SCM for $1-2 \mathrm{~cm}$ superiorly and to the level of clavicle inferiorly. The posterior aspect of the SCM was then dissected free from the underlying carotid sheath. The clavicular and sternal heads of SCM underlying investing cervical fascia, were divided at this level by electrocautery (Fig.-2a, 2b). Hemostasis was ensured.

Transected ends of the muscle were than dissected free from the surrounding fascia and carotid sheath with caution (Fig. - 3a, 3b ).

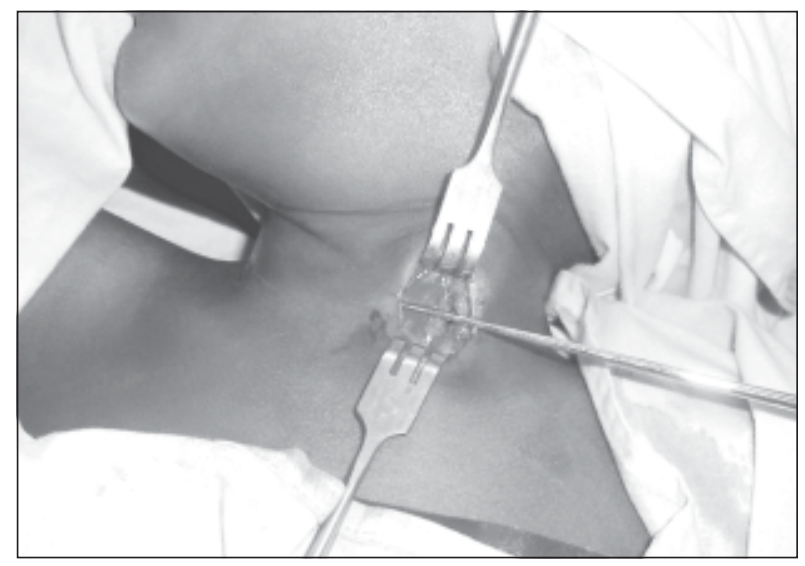

Fig.-2b : Division of SCM 


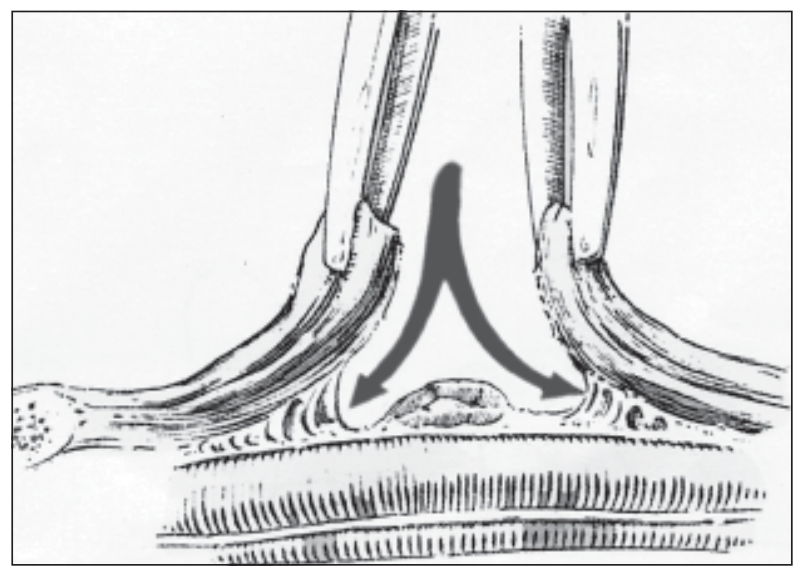

Fig.-3a : Transected ends of SCM

Surrounding cervical fascia was also released as they may contribute to contracture. Wound is then palpated to ensure that all contracted tissue is released. The external jugular vein was not divided. After ensuring hemostasis, wound was closed in layers - Platysma and skin. Post operative period was uneventful.

The patients were maintained $30^{\circ}$ up position for first 24 hours and then the patients were allowed to go home and advised for limited physiotherapy on the same day and regular physiotherapy from fifth post operative day. Follow up was given on $7^{\text {th }}$ Post operative day and after 3 and 6 months.

\section{Results}

Patients age range was from 5 days to 15 years of which eleven were female and five male. SCM was shortened in all cases (9 on right side and 7 on left side) Right: Left $=1.3: 1$. Of 16 patients, 3 neonates, 8 infants and 5 were more than 1 year age. There was no associated anomaly. Thirteen patients had the history of normal vaginal delivery, one patient had the history of forceps delivery and two had the history caesarian operation.

Table-I

Mode of delivery

\begin{tabular}{lc}
\hline Mode of delivery & No of Patients \\
\hline Ceserian Section & 2 \\
Normal Vaginal Delivery & 13 \\
Forceps (First Born Baby) & 1 \\
\hline Total & 14 \\
\hline
\end{tabular}

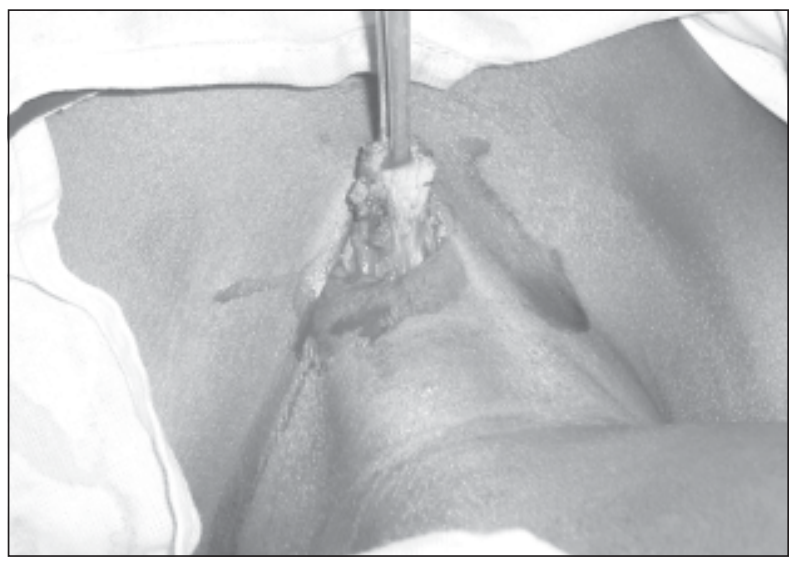

Fig.-3b : Dissection of Transected ends of SCM

Among the normal vaginal delivery patients, five had prolonged labour, of which four was first-born baby (Table-I). None advice the history of breech delivery. There is no family history of torticollis in any patient. There are history of sternomastoid tumor in two patients in neonatal period, one was corrected by physiotherapy during infant life but another didn't get corrected by physiotherapy till the age of one year and we did surgery at the age of 18 months.

Table-II

Treatment result

\begin{tabular}{lcc}
\hline Mode of treatment & No of patients & Cured n (\%) \\
\hline $\begin{array}{l}\text { Conservative } \\
(<1 \text { year age) }\end{array}$ & 11 & $10(91)$ \\
$\begin{array}{l}\text { Surgery } \\
(>1 \text { year age) }\end{array}$ & 5 & $5(100)$ \\
\hline
\end{tabular}

Out of 11 neonates and infants 10 cured conservatively with physiotherapy (Table-II) and another one significantly improved. Total- $V$ were treated surgically. Post operative period was uneventful and there was no complication.

Results of operation were assessed subjectively by clinical evaluation, patient's response and critical analysis by peers regarding appearance, chin position, position of head and face. Over all result is excellent in respect of movement of head and neck and position of face. On $7^{\text {th }}$ Post operative day, all of the patient could move their head and neck as they wanted. There was no tilting of head and child could look forward. There were no complications. After 6 months all patients looked like a normal baby. There was no recurrence. Results of operation are shown in figures 4 and 5 . 


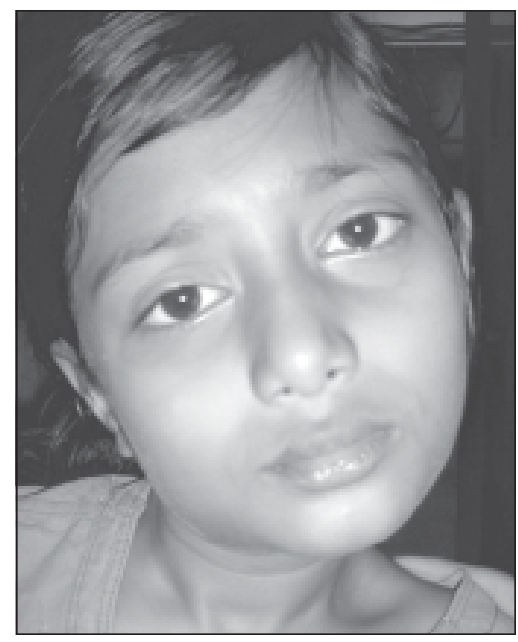

Fig.-4a : Preoperative CMT

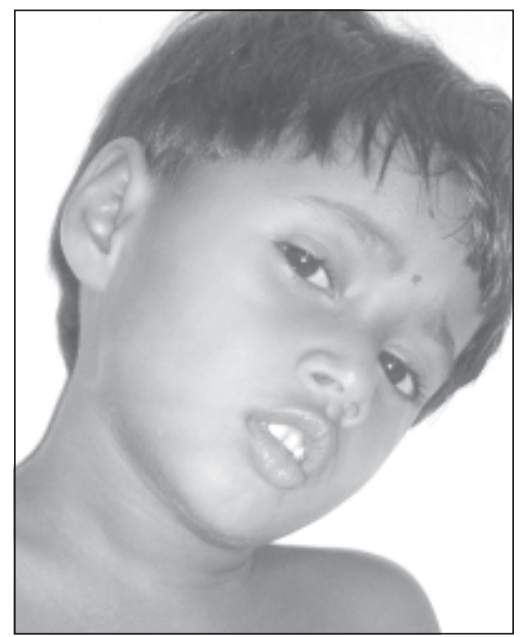

Fig.-5a : Preoperative CMT

\section{Discussion}

CMT patient's head always remain tilted to the affected side, they can't look forward, can't rotate the head and neck as they want. They have to move the whole body to see the side objects. Untreated cases develop mandibular hypoplasia, facial hemihypoplasia, skeletal deformity of face, etc which leads to permanent disfiguration. So CMT patients suffer both functional and cosmetic problems ${ }^{1,2,4}$.

Though in literature, the incidence of CMT is 1 in every 300 live births ${ }^{4}$, but we have no data about CMT in Bangladesh.

The optimal management of CMT has been urged for many years. Most agree that physiotherapy is the mainstay of the treatment. In literature success rate

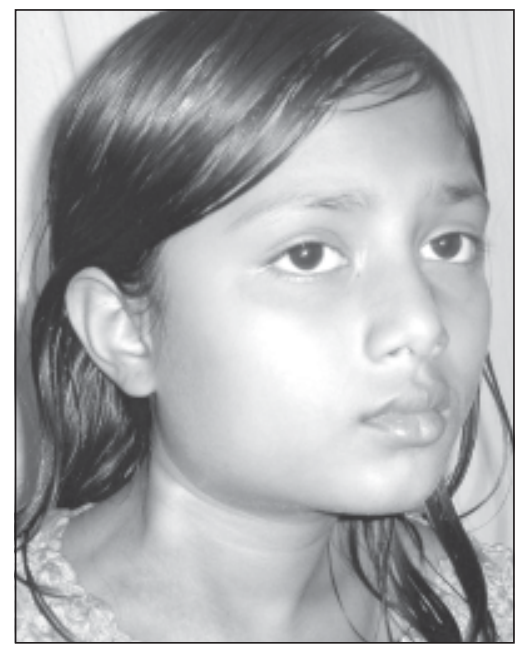

Fig.-4b : Post-operative CMT

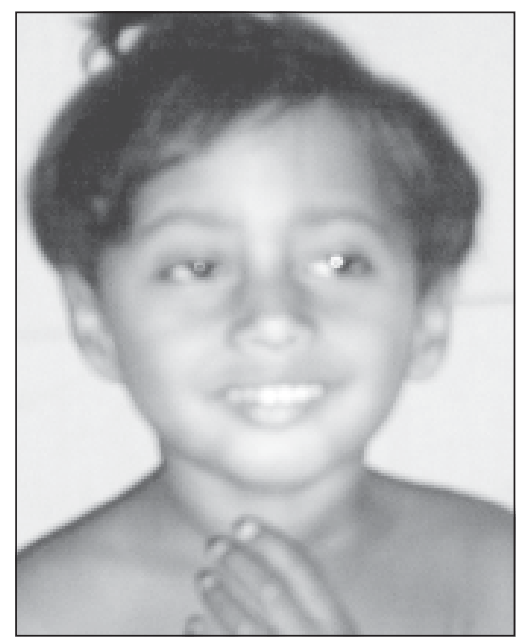

Fig.-5b : Post-operative CMT

of physiotherapy is $69-91 \%^{1}$. In the present study it is $91 \%$ which is within the limit of international studies.

Surgery is usually reserved for patients whose conditions were persistent beyond the age of one year or when cervical function and facial deformities are unacceptable ${ }^{11}$.

There are various techniques of surgery of which division of both sternal and clavicular head of sternocleidomastoid muscle is easy and less time consuming. It can be done as a day case surgery. There is no chance of injury to the accessory nerve as it passes more superiorly, external jugular vein can also be preserved ${ }^{11}$. Movement of the head and neck depends upon the synergistic and antagonistic activities of the different cervical muscles, such as 
splenius capitis, trapezius, platysma, the longus coli, the longus capitis, rectus capitis, etc ${ }^{15}$. So, in absence of CMT in one side will not interfere with the movement of head and neck ${ }^{15}$.

In the present study, right : left sternocleidomastoid ratio of 1.3:1 which corresponds with the study of others ${ }^{16}$. There are records of family history of CMT in $3.6 \%{ }^{16}$ but no such finding was found in the present study which also corresponds with the study of others ${ }^{17}$. Out 16 patients, there are history of sternocleidomastoid tumour in two patients which also corresponds with the findings of other studies ${ }^{6,18}$.

Facial asymmetry and plagiocephaly are common, though not invariable associated anomaly with CMT. Both believed to be secondary to the CMT. It may happen in neglected cases of CMT. In this study, the patients are of early ages. Reported co-existence of hip dysplasias with CMT varies from $0.6 \%$ to $20 \%$ but no such condition or any other associated anomalies like others were found in the present study ${ }^{16,17}$. There were no wound infections or any other complications in the present study. Though in reported literature recurrent CMT after surgical treatment is about 3\% but we have no such record ${ }^{19}$.

\section{Conclusion}

Early detection and initiation of physical therapy is related to improved outcomes and less need for surgical treatment of the SCM. Repositioning is a required element of early management of torticollis. Most of the patients of congenital muscular torticollis can be treated conservatively during infantile period. Division of both sternal and clavicular heads of sternocleidomastoid muscle in case of persistent torticollis, beyond the age of one year is a safe and simple method of surgery with an excellent result in respect of movement of head and neck, position of head, appearance and comments of peers.

\section{References}

1. Cheng JCY, Tang SP, Chen TMK. The clinical presentation and outcome of treatment of congenital muscular torticollis in infants. A study of 1,086 cases. J Pediatr Surg 2000; 35: 109196.

2. Canale ST, Griffin DW, Hubbard CN. Congenital muscular torticollis: a long term follow-up. J Bone Joint Surg Am 1982; 64: 810-16.
3. Wolfort PG, Kanter MA, Millar LB. Torticollis. Plastic Recostr Surg 1989; 84: 682 -92.

4. Clarren SK, Smith DW, Hanson JW. Helmet treatment for plagiocephaly and congenital muscular torticollis. J Pediatr 1979; 94: 43-46.

5. Cheng JCY, Au AWY. Infantile torticollis: a review of 624 cases. J Pediatr Orthop 1994; 14: 802-07.

6. Thomsen JR, Koltai PJ. Sternomastoid tumor of infancy. Ann Otol Rhinol Laryngol 1989; 98: 955-59.

7. De Chalain TMB, Katz A. Idiopathic muscular torticollis in children : the Cape Town experience. Br J Plastic Surg 1992; 45: 297-301.

8. Binder H, Eng GD, Gaiser JF. Congenital muscular torticollis: results of conservative management with long-term follow-up in 85 cases. Arch Phys Med Rehabil 1987; 68: 222-25.

9. Karmel-Ross K. Torticollis: Differential Diagnosis, Assessment and Treatment, Surgical Management and Bracing. Binghamton, NY: Haworth Press; 1997.

10. Shepherd R. Torticollis. In: Shepherd R, editor. Physiotherapy in Pediatrics. 3rd ed. Woburn, MA: Butterworth- Heinemann; 1995. 293-302.

11. Hihrschl RB. Sternomastoid torticollis. In: Spitz L, Coran AG, editors. Rob \& Smith's Operative surgery Pediatric Surgery. $5^{\text {th }}$ ed. London: Chapman and Hall; 1995; p. 71-75.

12. Loder RT. The cervical spine. In: Morrissy RT, Weinstein SL, editors. Lovell and Winter's Pediatric Orthopedics. 5th ed. Philadelphia: Lippincott Williams \& Wilkins; 2001. p. 799-836.

13. Stassen LF, Kerawala CJ. New surgical technique for the correction of congenital muscular torticollis. $\mathrm{Br} \mathrm{J}$ Oral Maxillofac Surg 2000; 38: 142-47.

14. Burstein F, Cohen S. Endoscopic surgical treatment for congenital muscular torticollis. Plast Reconstr Surg 1998; 101: 20-24.

15. Williams PL, Warwick R. Editors, Myology, Gray's Anatomy. $36^{\text {th }}$ ed, Churchill Living Stone, UK. 1980: $536-547$. 
16. Ling CM, Balachandran N. A prospective study of sternomastoid tumour in a closed community. Proceedings of the Tenth Singapore-Malaysia Congress of Medicine 1975; 10: 233-6.

17. Freed SS, Coulter-O'Berry C. Identification and treatment of congenital muscular torticollis in infants. JPO 2004; 16: 18-23.

18. Davids JR, Wenger DR, Mubarak SJ, Congenital muscular torticollis: sequel of intrauterine or perinatal compartment syndrome. J Pediatr Orthop 1993, 13: 141-47.

19. Wirth CJ, Hagena FW, Wuelker N, Siebert WE. Biterminal Tenotomy for the treatment of congenital muscular torticollis. J Bone Joint Surg Am 1992; 74: 427-32. 